\title{
Calcium-Binding Proteins in Bovine Milk: Calcium-Binding Properties and Amino Acid Composition
}

\author{
Masaaki TAMURA, Tsuneyuki OKU, and Norimasa Hosoya ${ }^{1}$ \\ Department of Nutrition, School of Health Sciences, \\ Faculty of Medicine, University of Tokyo, \\ Bunkyo-ku, Tokyo 113, Japan
}

(Received April 9, 1982)

\begin{abstract}
Summary The $\mathrm{Ca}^{2+}$-binding properties and amino acid compositions of two calcium-binding proteins (mCaBP-3 and mCaBP-4) purified from bovine milk were studied. mCaBP-3 was identified as a $\mathrm{Ca}^{2+}$-bound type and $\mathrm{mCaBP}-4$ as a $\mathrm{Ca}^{2+}$-free type by means of ion-exchange chromatography on a DEAE-Sephadex A-25 column. In polyacrylamide gel disc electrophoresis, both mCaBP-3 and mCaBP-4 had the same mobility of $R_{f}=0.73$ and the addition of $5 \mathrm{mM} \mathrm{CaCl}_{2}$ to the electrode buffer decreased the mobility from $R_{f}=0.73$ to $R_{f}=0.49$. $\mathrm{mCaBP}-3$ and $\mathrm{mCaBP}-4$ consisted of 120 and 122 amino acid residues, respectively. The molecular weights were 13,758 and 13,967 , respectively. The amino acid compositions of the two milk CaBPs very closely resembled each other. Both milk CaBPs were rich in aspartic acid, glutamic acid, leucine and lysine, but did not contain trimethylated lysine and amino sugar. An interesting feature is that each milk CaBP contained eight cysteine sulfone and three tryptophan residues per molecule. From these results, it is suggested that $\mathrm{mCaBP}-3$ and $\mathrm{mCaBP}-4$ are identical protein and that $\mathrm{mCaBP}-3$ is formed from mCaBP-4 by means of a conformational change by binding of $\mathrm{Ca}^{2+}$. Thus, $\mathrm{mCaBP}-3$ is a holoprotein and $\mathrm{mCaBP}-4$ is an apoprotein. Furthermore, it is suggested that milk CaBP is different from calmodulin, troponin $\mathrm{C}$ and vitamin $\mathrm{D}$-dependent calcium-binding protein.
\end{abstract}

Key Words calcium-binding protein, bovine milk, $\mathrm{Ca}^{2+}$-binding properties, amino acid composition

Calcium is involved in the regulation of a variety of cellular enzyme systems and in most types of cell motility $(1,2)$. It is possible that $\mathrm{Ca}^{2+}$ might not act in its free ionic form but rather requires the presence of a binding protein. Calciumbinding proteins such as calmodulin and vitamin D-dependent calcium-binding protein have been commonly identified in many tissues of many avian and mammalian species $(3,4)$.

\footnotetext{
1 田村正明，奥 恒行，細谷憲政
} 
Previously, we demonstrated that two different calcium-binding proteins (mCaBP-3 and mCaBP-4) which are clearly different from casein can be purified from bovine milk (5). The physicochemical properties of the two CaBPs resembled each other very closely. Both milk $\mathrm{CaBPs}$ had a molecular weight of approximately 15,000 and two kinds of binding sites for $\mathrm{Ca}^{2+}\left(K_{\mathrm{d}}=1.7 \times 10^{-6} \mathrm{M}\right.$ and $K_{\mathrm{d}}=$ $\left.5.1 \times 10^{-4} \mathrm{M}\right)$, and were heat-stable. Furthermore, these milk CaBPs modulated galactosyltransferase activity in a $\mathrm{Ca}^{2+}$-dependent manner, as well as calmodulin (6).

On the other hand, calcium-binding proteins such as calmodulin $(7,8)$, troponin $\mathrm{C}(8)$ and vitamin $\mathrm{D}$-dependent calcium-binding protein $(9)$ elicited a large conformational change by the binding of $\mathrm{Ca}^{2+}$ to the affinity sites. Although the physicochemical properties of $\mathrm{mCaBP}-3$ and $\mathrm{mCaBP}-4$ very closely resembled each other, the fact that they were separated by ion-exchange column chromatography on DEAE-Sephadex A-25 seems to suggest that either mCaBP-3 or mCaBP-4 causes a $\mathrm{Ca}^{2+}$-dependent conformational change.

The current research was designed to further characterize the milk CaBPs in the absence and presence of $\mathrm{Ca}^{2+}$ and to analyze the amino acid composition.

\section{MATERIALS AND METHODS}

1. Isolation and purification of bovine milk CaBPs. Two milk CaBPs were purified from unpasteurized bovine skim milk as previously described (5). The skim milk (about $20 \mathrm{ml}$ ) was fractionated using a Sephadex G-100 column $(2.6 \times 64 \mathrm{~cm})$ equilibrated with $10 \mathrm{~mm}$ imidazole buffer $\left(\mathrm{pH} 6.9\right.$ at $\left.5^{\circ} \mathrm{C}\right)$ containing $55 \mathrm{~mm} \mathrm{KCl}$ and $25 \mathrm{~mm} \mathrm{NaCl}$ (IKN buffer). The main peak with ${ }^{45} \mathrm{Ca}$-binding activity, using the Chelex-100 procedure, was collected and further purified by ion-exchange chromatography on a DEAE-Sephadex A-25 column $(1.5 \times 36 \mathrm{~cm})$ with a linear gradient of 25 to $400 \mathrm{~mm} \mathrm{NaCl}$ in IKN buffer. The two major peaks eluted at the concentrations of $0.17 \mathrm{M}$ and $0.21 \mathrm{M} \mathrm{NaCl}$ were respectively collected, and then subjected to the final step of separate gel filtration on Sephadex G-75 column $(1.8 \times 90 \mathrm{~cm})$ chromatography. The milk CaBPs (mCaBP-3 and mCaBP-4) obtained appeared as a single homogeneous band on polyacrylamide gel disc electrophoresis.

2. Identification of $m C a B P-3$ and $m C a B P-4$ by ion-exchange chromatography. The ion-exchange chromatography was carried out on a DEAE-Sephadex A-25 column $(1.5 \times 36 \mathrm{~cm})$ to identify $\mathrm{mCaBP}-3$ and $\mathrm{mCaBP}-4$. The column was eluted with a linear gradient of 25 to $400 \mathrm{~mm} \mathrm{NaCl}$ in the IKN buffer with either $1 \mathrm{~mm}$ $\mathrm{CaCl}_{2}$ or $1 \mathrm{mM}$ ethyleneglycol-bis $\left(\beta\right.$-aminoethyl ether) $N, N^{\prime}$-tetraacetic acid (EGTA). The flow rate was $10 \mathrm{ml}$ per hr. The elution profile was monitored by absorbance at $280 \mathrm{~nm}$.

3. Amino acid analysis. The amino acid analysis was performed by the method of Inglis and Liu (10) with a slight modification. The purified CaBPs (exactly $1 \mathrm{mg}$ protein each) were dialyzed exhaustively against distilled water, lyophilized and then hydrolyzed in $1 \mathrm{ml}$ of $4 \mathrm{~N}$ methane sulfonic acid in evacuated tubes at $115^{\circ} \mathrm{C}$ for 
24, 48 and $72 \mathrm{hr}$. After the samples were neutralized with the same volume of $4 \mathrm{~N}$ $\mathrm{NaOH}$, the mixtures were reduced by $4 \mu$ moles dithiothreitol, and then sulfonated by $200 \mu$ moles sodium tetrathionate for analysis of cystine and cysteine. After sulfonation, each hydrolysate was lyophilized again and dissolved in $0.2 \mathrm{M}$ sodium citrate buffer ( $\mathrm{pH}$ 2.2). The analysis of amino acid was carried out on a JEOL AH6 amino acid analyzer (Japan Electric Co., Japan).

4. Other methods. Analytical disc electrophoresis was carried out essentially by the method of Davis (11) using 7.5\% polyacrylamide gel. The $\mathrm{Ca}^{2+}$-binding activity was measured by the competitive binding assay of Wasserman et al. (12) using 50\% Chelex-100 chelating resin suspension. Protein concentration was determined by the method of Lowry et al.(13) with crystalline bovine serum albumin as a standard.

5. Chemicals. ${ }^{45} \mathrm{CaCl}_{2}(21.4 \mathrm{mCi} / \mathrm{mgCa})$ and Omnifluor were purchased from New England Nuclear (Boston, MA). Sephadex G-100 and G-75, and DEAESephadex A-25 were obtained from Pharmacia Fine Chem. (Uppsala, Sweden). Chelex-100 chelating resin was purchased from Bio-Rad Lab. (Richmond, CA). Other chemicals were of analytical grade.

\section{RESULTS}

1. Interrelation of $m C a B P-3$ and $m C a B P-4$ on ion-exchange column chromatography

Calcium-binding proteins such as calmodulin $(7,8)$, troponin $\mathrm{C}(8)$ and vitamin D-dependent calcium-binding protein $(9)$ are known to undergo a conformational change by binding of $\mathrm{Ca}^{2+}$. Thus, a certain calcium-binding protein can be observed as two different proteins depending on the binding of $\mathrm{Ca}^{2+}$.

When the purified $\mathrm{mCaBP}-3$ was again chromatographed using on a DEAESephadex A-25 ion-exchange column equilibrated with a regular IKN buffer, two protein peaks were detected at positions corresponding to mCaBP-3 and $\mathrm{mCaBP}-4$, respectively (Fig. 1). However, when the IKN buffer containing $1 \mathrm{mM} \mathrm{CaCl}_{2}$ was used instead of the regular IKN buffer, the re-chromatogram of mCaBP-3 was nearly the same as original chromatogram of mCaBP-3 (Fig. 2). Further, in the calcium-free buffer system containing $1 \mathrm{~mm}$ EGTA, the purified mCaBP-3 was eluted at the position corresponding to $\mathrm{mCaBP}-4$ and was not detected at the position of $\mathrm{mCaBP}-3$ (Fig. 2). On the other hand, when purified $\mathrm{mCaBP}-4$ was rechromatographed using the same ion-exchange column, the protein peak was detected at the position of $\mathrm{mCaBP}-3$ in the IKN buffer system containing $1 \mathrm{~mm}$ $\mathrm{CaCl}_{2}$ and at the position of mCaBP-4 in the $\mathrm{Ca}^{2+}$-free buffer system containing $1 \mathrm{~mm}$ EGTA, respectively (data are not shown). These results strongly suggest that mCaBP-3 is a charge-isomer of mCaBP-4 which is induced by binding of $\mathrm{Ca}^{2+}$. Thus, they indicate that $\mathrm{mCaBP}-3$ and $\mathrm{mCaBP}-4$ are a holoprotein and an apoprotein, respectively. 


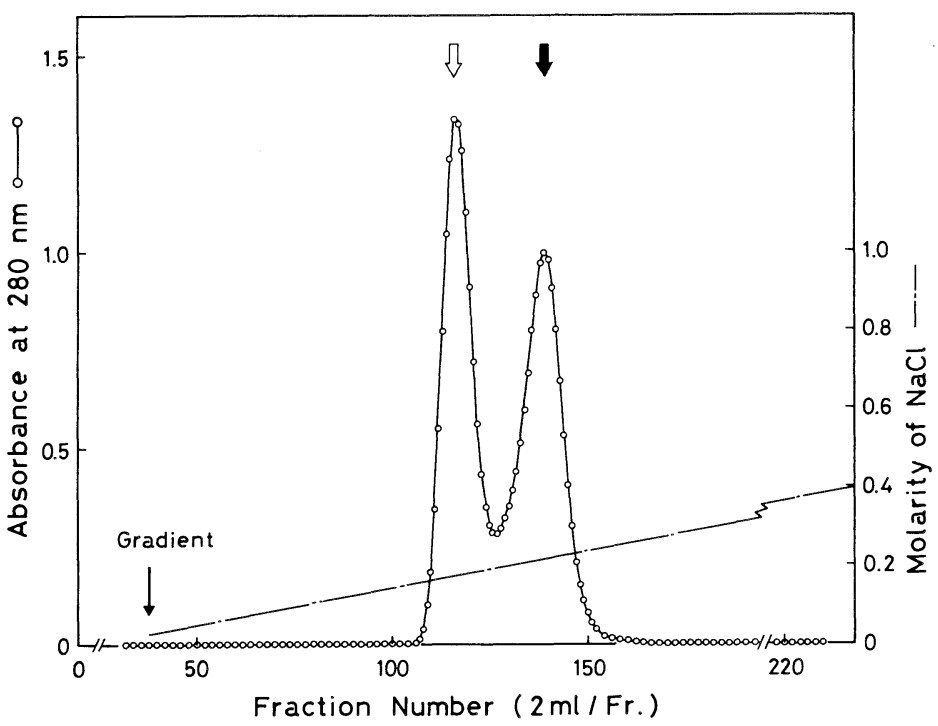

Fig. 1. Re-chromatography of mCaBP-3 purified from bovine milk on a DEAESephadex A-25 column. mCaBP-3 purified from bovine skim milk (about $38 \mathrm{mg}$ ) was applied again to a DEAE-Sephadex A-25 column $(1.5 \times 36 \mathrm{~cm})$ equilibrated with IKN buffer ( $\mathrm{pH} 6.9$ at $\left.5^{\circ} \mathrm{C}\right)$ and eluted with a linear gradient of $\mathrm{NaCl}(25$ $400 \mathrm{~mm}$ ) in the same buffer. The flow rate was $10 \mathrm{ml}$ per hr. Two $\mathrm{ml}$ of fractions were collected and monitored for protein concentration by absorbance at $280 \mathrm{~nm}$. The arrows represent the positions of $\mathrm{mCaBP}-3$ (open arrow) and $\mathrm{mCaBP}-4$ (solid arrow) eluted with ion-exchange chromatography on the DEAE-Sephadex A-25 column, which was carried out under the same conditions as above, in the step of purification of milk CaBPs. mCaBP-3 and mCaBP-4 were eluted at the concentration of $0.17 \mathrm{M}$ and $0.21 \mathrm{M} \mathrm{NaCl}$, respectively, on a linear gradient of $\mathrm{NaCl}$. See the METHOD for details.

2. Effect of $\mathrm{Ca}^{2+}$ on mobility of milk CaBP in polyacrylamide gel disc electrophoresis

One of the characteristics of calmodulin is that the migration rate in polyacrylamide gel disc electrophoresis changes dramatically by the binding of $\mathrm{Ca}^{2+}$ (14). When the purified $\mathrm{mCaBP}-3$ and $\mathrm{mCaBP}-4$ were analyzed by $7.5 \%$ polyacrylamide gel disc electrophoresis without the additional $\mathrm{Ca}^{2+}$ to the samples and the electrode buffer, the relative mobilities of the two $\mathrm{mCaBPs}$ were the same, the values being 0.73 (Fig. 3). In disc electrophoresis using the buffer containing $5 \mathrm{mM} \mathrm{CaCl}_{2}$, the relative mobilities of the two CaBPs decreased from $R_{f}=0.73$ to $R_{f}=0.49$. The difference of electrophoretic mobility between mCaBP-3 and mCaBP-4 was neither observed in the absence nor the presence of $\mathrm{Ca}^{2+}$. These results indicate that the electric charge of milk CaBPs is greatly affected by the binding of $\mathrm{Ca}^{2+}$. 


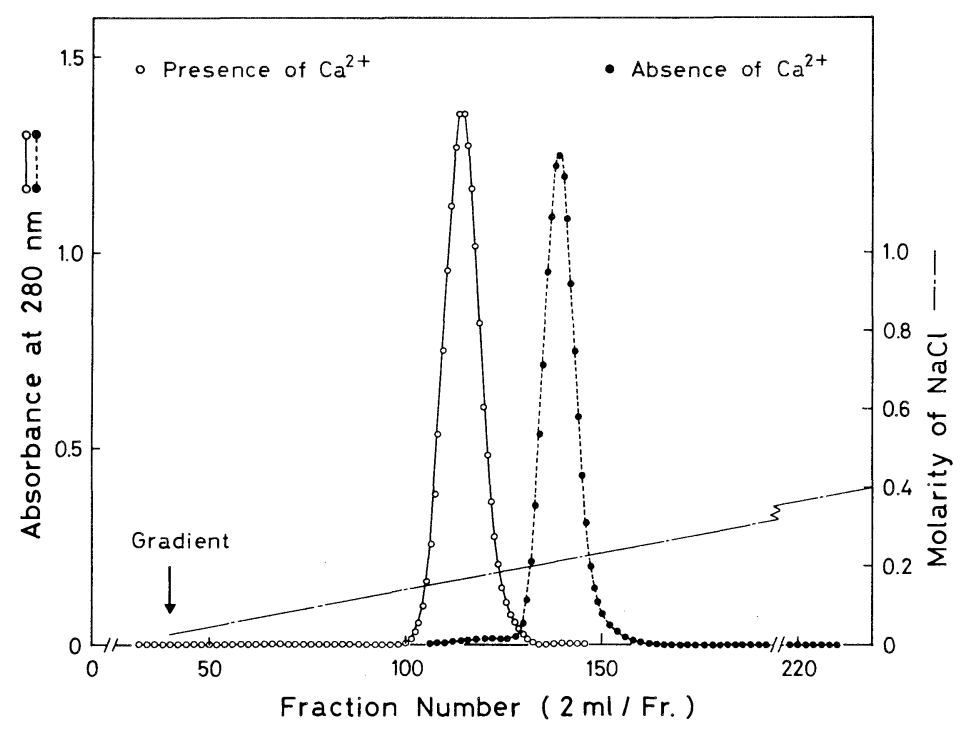

Fig. 2. Re-chromatography of mCaBP-3 purified from bovine milk on a DEAESephadex A-25 column in the presence and absence of $\mathrm{Ca}^{2+}$. mCaBP-3 (about $15 \mathrm{mg}$ each) purified from bovine milk was applied to DEAE-Sephadex A-25 columns $(1.5 \times 36 \mathrm{~cm})$ equilibrated with IKN buffer containing either $1 \mathrm{mM} \mathrm{CaCl}_{2}$ or $1 \mathrm{~mm}$ EGTA. Each column was eluted with a linear gradient of $\mathrm{NaCl}(25-400 \mathrm{~mm})$ in IKN buffer containing either $1 \mathrm{~mm} \mathrm{CaCl}(\bigcirc-\mathrm{O})$ or $1 \mathrm{~mm}$ EGTA $(\bullet---\bullet)$. The flow rate was $10 \mathrm{ml}$ per hr. Two $\mathrm{ml}$ of fractions were collected.

\section{Amino acid compositions of $m C a B P-3$ and $m C a B P-4$}

The above results suggest strongly that $\mathrm{mCaBP}-3$ and $\mathrm{mCaBP}-4$ are the same protein and therefore, the respective amino acid compositions were analyzed. The results are shown in Table 1 . $\mathrm{mCaBP}-3$ consisted of 120 amino acid residues and the calculated molecular weight was 13,758 . mCaBP-4 consisted of 122 amino acid residues and the calculated molecular weight was 13,967 . Both milk CaBPs were rich in aspartic acid, glutamic acid, leucine and lysine. Trimethylated lysine and amino sugar could not be detected. The amino acid compositions of mCaBP-3 and $\mathrm{mCaBP}-4$ very closely resembled each other. An interesting feature was that each milk $\mathrm{CaBP}$ contained eight cysteine sulfone and three tryptophan residues per 'molecule.

\section{DISCUSSION}

In order to clarify the situation with regard to bovine milk $\mathrm{CaBP}, \mathrm{Ca}^{2+}$ binding properties and amino acid compositions of mCaBP-3 and mCaBP-4 were further investigated. When purified $\mathrm{mCaBP}-3$ or $\mathrm{mCaBP}-4$ was fractionated again by ion-exchange chromatography using a DEAE-Sephadex A-25 column equili- 


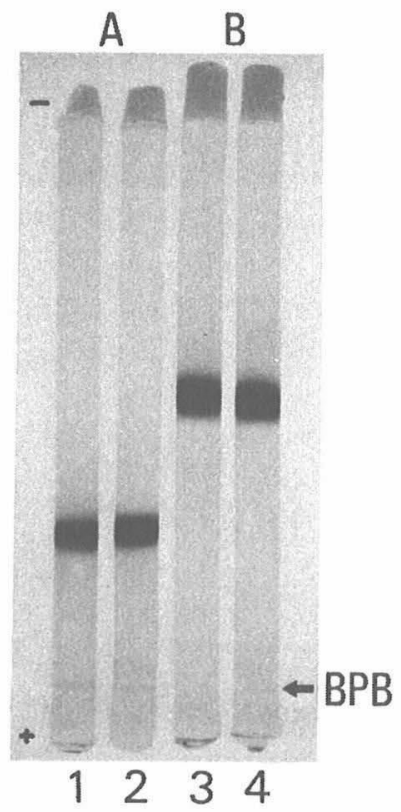

Fig. 3. Change of electrophoretic mobilities of $\mathrm{mCaBP}-3$ and $\mathrm{mCaBP}-4$ by binding of $\mathrm{Ca}^{2+}$. Disc electrophoresis was carried out essentially by the method of Davis (II) using $7.5 \%$ polyacrylamide gel. Group A: no addition of $\mathrm{CaCl}_{2}$ to either sample and electrode buffer. Group B: addition of $5 \mathrm{mM} \mathrm{CaCl}_{2}$ to both samples and electrode buffer. No. 1 and 3, mCaBP-3 (20 $\mu \mathrm{g}$ protein); No. 2 and 4 , mCaBP-4 $(20 \mu \mathrm{g}$ protein).

brated with the regular IKN buffer, the protein was detected at two positions corresponding to $\mathrm{mCaBP}-3$ and $\mathrm{mCaBP}-4$. However, when $\mathrm{Ca}^{2+}$-free buffer (regular IKN buffer+EGTA) or $\mathrm{Ca}^{2+}$-containing buffer (regular IKN buffer $+\mathrm{CaCl}_{2}$ ) was used for the column chromatography, only one peak which corresponded to $\mathrm{mCaBP}-4$ or $\mathrm{mCaBP}-3$, respectively, was eluted. These facts indicate that a portion of the $\mathrm{Ca}^{2+}$ bounds to $\mathrm{mCaBP}-3$ is removed by the ion-exchange resin and that mCaBP-4 binds the $\mathrm{Ca}^{2+}$ contaminating in the regular IKN buffer at trace level $\left(<10^{-6} \mathrm{M}\right)$ during the ion-exchange column chromatography. Thus, these results suggest that $\mathrm{mCaBP}-3$ is identical to $\mathrm{mCaBP}-4$. The facts that the amino acid compositions of the two milk CaBPs closely resembled each other and that they crossreacted immunologically (5), strongly suggest that $\mathrm{mCaBP}-3$ and $\mathrm{mCaBP}-4$ are charge-isomers induced by the binding of $\mathrm{Ca}^{2+}$. Further, it is implied that the binding of $\mathrm{Ca}^{2+}$ to the binding sites in the milk $\mathrm{CaBP}$ elicits a large conformational change. This conformational change by binding of $\mathrm{Ca}^{2+}$ is particularly characteristic in calcium-binding proteins such as calmodulin $(7,8)$, troponin $\mathrm{C}(8)$ and vitamin D-dependent calcium-binding protein (9).

The electrophoretic mobilities of calmodulin(14) and vitamin D-dependent 
Table 1. Amino acid compositions of mCaBP-3 and mCaBP-4.

$\mathrm{mCaBP}-3$ and $\mathrm{mCaBP}-4$ purified from bovine skim milk were hydrolyzed in $4 \mathrm{~N}$ methane sulfonic acid at $115^{\circ} \mathrm{C}$ for 24,48 , and $78 \mathrm{hr}$. Values are obtained by extrapolation to zero hydrolysis time and are expressed as minimum residues per molecule. See text for details.

\begin{tabular}{lrr} 
& \multicolumn{2}{c}{ Integer residues/molecule } \\
\cline { 2 - 3 } \multicolumn{1}{c}{ Amino acid } & mCaBP-3 & mCaBP-4 \\
\hline Aspartic acid & 20 & 20 \\
Threonine & 7 & 7 \\
Serine & 6 & 6 \\
Glutamic acid & 13 & 13 \\
Proline & 2 & 2 \\
Glycine & 7 & 7 \\
Alanine & 3 & 4 \\
Valine & 6 & 6 \\
Cysteine sulfone & 8 & 8 \\
Methionine & 1 & 1 \\
Isoleucine & 7 & 7 \\
Leucine & 13 & 13 \\
Tyrosine & 4 & 4 \\
Phenylalanine & 4 & 4 \\
Tryptophan & 3 & 3 \\
Lysine & 12 & 12 \\
Histidine & 3 & 4 \\
Arginine & 1 & 1 \\
\hline Total residues & 120 & 122 \\
Molecular weight & 13,758 & 13,967 \\
\hline
\end{tabular}

calcium-binding protein (15) are delayed by the binding of $\mathrm{Ca}^{2+}$. This change in mobilities, also, depends on a conformational change of the protein. In polyacrylamide gel disc electrophoresis, $\mathrm{mCaBP}-3$ and $\mathrm{mCaBP}-4$ had the same mobility of $R_{f}=0.73$, in spite of the $\mathrm{Ca}^{2+}$ bound to $\mathrm{mCaBP}-3$ not previously being removed from the protein. The $\mathrm{Ca}^{2+}$ bound to $\mathrm{mCaBP}-3$ must be removed by the potential difference, and mCaBP-3 transferred to the $\mathrm{Ca}^{2+}$-free form, mCaBP-4. On the other hand, the mobilities of both $\mathrm{mCaBP}-3$ and $\mathrm{mCaBP}-4$ were delayed from $R_{f}=0.73$ to $R_{f}=0.49$ by the addition of excess calcium to the electrode buffer. This change of mobility suggests the involvement of a large change of the electric charge dependent upon a conformational change of milk CaBP by binding of $\mathrm{Ca}^{2+}$.

Calmodulin characteristically contains trimethylated lysine, but not cystein and tryptophan(3). Vitamin D-dependent calcium-binding protein also did not contain cystein and tryptophan (4). Calmodulin contains aspartic acid and glutamic acid at the level of approximately $34 \%$ of total amino acid residues present (3). Milk $\mathrm{CaBP}$ was rich in acidic amino acids such as aspartic acid and glutamic acid, and 
further contains eight cystein sulfones and three tryptophans, but not trimethylated lysine. Therefore, milk CaBP is apparently different from calmodulin, troponin $\mathrm{C}$ and vitamin $\mathrm{D}$-dependent calcium-binding protein, though the several physicochemical properties of milk CaBP are similar to those of other CaBPs.

Calmodulin is known to function in the intracellular system(1). One of its functions is to activate phosphodiesterase via the enzyme-calmodulin complex which is induced by the binding of $\mathrm{Ca}^{2+}(16)$. Milk CaBP can also stimulate the enzyme activity such as galactosyltransferase in the presence of $\mathrm{Ca}^{2+}$, though it is abundant in secretions such as milk. This enzyme activation may involve the same mechanism as that of phosphodiesterase by calmodulin.

The amino acid composition of purified milk CaBP was closely similar to that of $\alpha$-lactalbumin reported elsewhere (17). Further, rabbit anti-mCaBP-3 antiserum crossreacted with $\alpha$-lactalbumin in micro-Ouchterlony double immunodiffusion (18). Therefore, milk CaBP may be identical to $\alpha$-lactalbumin involved in lactose synthesis in mammary gland.

This work was supported in part by grants from The Morinaga Hōshi-Kai. We wish to thank Dr. Takashi Abe, Laboratory of Insect Toxicology, Institute of Physical and Chemical Research, Saitama, Japan, for the excellent assistance given in the amino acid analysis.

\section{REFERENCES}

1) Cheung, W. Y. (1980): Calmodulin plays a pivotal role in cellular regulation. Science, 207, 19-27.

2) Dedman, J. R., Brinkley, B. R., and Means, A. R. (1979): Regulation of microfilaments and microtubules by calcium and cyclic AMP. Adv. Cyclic Nucleotide Res., 11, 131-174.

3) Wang, J. H., and Waisman, D. M. (1979): Calmodulin and its role in the secondmessenger system. Current Topics in Cellular Regulation, 15, 47-107.

4) Wasserman, R. H., Fullmer, C. S., and Taylor, A. N. (1978): The vitamin D-dependent calcium-binding proteins. in Vitamin D, ed. by Lawson, D. E. M., Academic Press Inc., New York, pp. 133-166.

5) Tamura, M., Oku, T., and Sugiura, K. (1981): Purification and characterization of calcium-binding protein from bovine milk. Jpn. J. Vet. Sci., 43, 539-551.

6) Tamura, M., Oku, T., and Hosoya, N. (1981): Calmodulin-like function of calciumbinding protein in bovine milk. J. Nutr. Sci. Vitaminol., 27, 489-492.

7) Klee, C. B. (1977): Conformational transition accompanying the binding of $\mathrm{Ca}^{2+}$ to the protein activator of $3^{\prime}, 5^{\prime}$-cyclic adenosine monophosphate phosphodiesterase. Biochemistry, 16, 1017-1024.

8) Dedman, J. R., Potter, J. D., Jackson, R. L., Johnson, J. D., and Means, A. R. (1977): Physicochemical properties of rat testis $\mathrm{Ca}^{2+}$-dependent regulator protein of cyclic nucleotide phosphodiesterase. Relationship of $\mathrm{Ca}^{2+}$-binding, conformational changes, and phosphodiesterase activity. J. Biol. Chem., 252, 8415-8422.

9) Szebeny, D. M. E., Obendorf, S. K., and Moffat, K. (1981): Structure of vitamin Ddependent calcium-binding protein from bovine intestine. Nature, 294, 327-333.

10) Inglis, A. S., and Liu, T. Y. (1970): The stability of cystine during acid hydrolysis of proteins and peptides. J. Biol. Chem., 245, 112-116. 
11) Davis, B. J. (1964): Disc electrophoresis-II. Method and application to human serum proteins. Ann. N. Y. Acad. Sci., 121, 404-427.

12) Wasserman, R. H., Corradino, R. A., and Taylor, A. N. (1968): Vitamin D-dependent calcium-binding protein. Purification and some properties. J. Biol. Chem., 243, 39783986.

13) Lowry, O. H., Rosebrough, N. J., Farr, A. L., and Randall, R. J. (1951): Protein measurement with folin phenol reagent. J. Biol. Chem., 193, 265-275.

14) Grand, R. J. A., Perry, S. V., and Weeks, R. A. (1979): Troponin C-like proteins (calmodulins) from mammalian smooth muscle and other tissues. Biochem. J., 177, 521-529.

15) Bruns, M. E. H., Fausto, A., and Avioli, L. V. (1978): Placental calcium-binding protein in rats. Apparent identity with vitamin D-dependent calcium binding protein from rat intestine. J. Biol. Chem., 253, 3186-3190.

16) Teshima, Y., and Kakiuchi, S. (1974): Mechanism of stimulation of $\mathrm{Ca}^{2+}$ plus $\mathrm{Mg}^{2+}$ dependent phosphodiesterase from rat cerebral cortex by the modulator protein and $\mathrm{Ca}^{2+}$. Biochem. Biophys. Res. Commun., 56, 489-495.

17) Brew, K., Castellino, F. J., Vanaman, T. C., and Hill, R. L. (1970): The complete amino acid sequences of bovine $\alpha$-lactalbumin. J. Biol. Chem., 245, 4570-4582.

18) Tamura, M., Oku, T., and Hosoya, N. (1981): Further characterization and physiological role of calcium-binding proteins from bovine milk. Proc. 91st Meet. Jpn. Soc. Vet. Sci., Tokyo, p. 36. 